\title{
Irreversible morphological changes contributing to depressed cardiac function after surgery for chronic aortic regurgitation
}

\author{
R M DONALDSON, R FLORIO, A F RICKARDS, J G BENNETT, M YACOUB, D N ROSS, \\ E OLSEN
}

From the National Heart Hospital and Cardiothoracic Institute, London

SUMMARY The timing of surgery in chronic aortic regurgitation remains a difficult problem. To identify variables predictive of postoperative haemodynamic improvement, changes in left ventricular mass, volume, morphology, and histochemistry were analysed in 67 patients undergoing surgery for chronic aortic regurgitation. Patients were divided into two groups: those in whom the left ventricular echo diameters returned to normal after operation (51 patients, group A), and those with postoperative dilatation (16 patients, group B). A preoperative biopsy was obtained in all patients; postoperative tissue samples were available in 13 patients (five from group A, eight from group B). Data were correlated with the postoperative clinical, haemodynamic state over a follow-up period of three years. Regression of hypertrophy was usually incomplete. Echocardiographic and angiographic data could not define the type and degree of dysfunction which was irreversible. Massive fibre hypertrophy (mean $34 \cdot 1 \mu \mathrm{m}$ ), moderately or severely increased interstitial fibrous tissue, reduced levels of the myofibrillar and mitochondrial enzymes adenosine triphosphates and succinate dehydrogenase in pre- and postoperative tissue samples correlated with persistent dilatation, cardiac failure, and early death (group B).

Irreversible morphological and functional changes contributed to a depressed cardiac function after operation. Preoperative ventricular biopsies are thus of prognostic importance in volume overload.

Patients undergoing aortic valve replacement for volume overload generally experience haemodynamic improvement and relief of presenting symptoms. In some instances, however, surgical correction does little to alter the course of the disease.

The extent to which clinical improvement is associated with regression of hypertrophy and abnormalities of ventricular function is not well known. ${ }^{12}$ In this study we analysed the changes in ventricular mass, volume, and histochemistry in a selected group of patients who underwent homograft aortic valve replacement for chronic aortic regurgitation, correlating these changes with the postoperative clinical state. In addition, preoperative data were examined in an effort to identify variables which might predict which patients could expect a good result from surgery and which might not.

\section{Patients and methods}

The dominant lesion requiring aortic valve replacement in all cases was chronic, severe aortic regurgitation, defined as at least grade $3 / 4$ on angiography. Those with multiple valvar abnormalities, coronary artery disease, or combined stenosis and regurgitation were not included. There were 49 men and 18 women aged 16 to 72 (mean age 58.5 years). Aetiologies of the aortic regurgitation included non-inflammatory root disease (29 patients), rheumatic, congenital, or infective disease of the valve cusps ( 30 patients), and inflammatory root disease (eight patients). A pre- or intraoperative biopsy was obtained in all patients, who were also selected on the basis of technically adequate serial echocardiograms and normal prosthetic function over a follow-up period of at least three years.

POSTOPERATIVE EVALUATION

All patients were re-evaluated non-invasively (chest radiography, electrocardiography, and echo- 
cardiography) at two weeks and six months after operation; studies were then performed at yearly intervals for a minimum of three years. Three out of these 67 patients died from cardiac failure, 18, 24, and 30 months after operation, respectively. Postoperative cardiac catheterisation was performed in 21 patients in whom cardiac symptoms persisted or recurred after valve replacement. In 13 of these 21 patients left ventricular biopsy was available for comparison with the intraoperative specimen.

\section{ELECTROCARDIOGRAPHY}

Standard 12 lead electrocardiograms were obtained before and after aortic valve replacement; the SokolowLyon voltage criteria and the Romhilt-Estes scores for left ventricular hypertrophy were computed.

\section{ECHOCARDIOGRAPHY}

Echocardiograms were obtained using a $12.5 \mathrm{~mm}, 2.25$ $\mathrm{MHz}$ transducer and an Ekoline $20 \mathrm{~A}$ ultrasound transceiver interfaced with a strip chart recorder. Echocardiographic measurement of the left ventricular transverse dimension at end-diastole, and thickness of the ventricular septum and free wall were obtained, with the ultrasound beam passing through the left ventricle caudal to the tips of the mitral leaflets, taking the peak of the $\mathbf{R}$ wave as end-diastole. Because of changes in septal motion after aortic valve surgery, end-systolic dimensions were not analysed. From the primary echocardiographic measurements, the left ventricular cross-sectional wall area was used as an estimate of left ventricular mass. ${ }^{3}$ Estimates on normal subjects were $16 \pm 4 \mathrm{~cm}^{2}$.

This cross-sectional area is useful for the serial assessment of left ventricular hypertrophy but assumes uniform distribution of the muscle mass around the ventricular circumference.

\section{CARDIAC CATHETERISATION}

Twenty-one patients underwent postoperative cardiac catheterisation. Recurrence of cardiac symptoms, and persistent cardiomegaly were the most frequent indications for the repeat studies. Ventricular function was assessed before and after valve replacement in all 21 cases using computerised, quantitative, radial analysis of segmental wall motion derived from the single plane left ventricular cineangiogram. ${ }^{+}$

\section{BIOPSIES}

Biopsy material was available before valve replacement in all 67 patients, the tissue being obtained either from preoperative endomyocardial biopsies or from an intraoperative biopsy. In 15 of these patients the bioptome tissue samples were also compared with an operative specimen, to establish whether the smaller bioptome samples were representative of the rest of the myo- cardium. Postoperative left ventricular biopsies were also available from 13 patients for comparison with the preoperative specimen. The endomyocardial biopsies were obtained with the modified Olympus fibreoptic bronchoscopic biopsy forceps introduced using the long sheath technique. ${ }^{5}$ Specimens were taken from the free wall of the left ventricle towards the apex; four to six tissue samples were obtained in each case. The intraoperative full thickness specimens were taken before cardiopulmonary bypass from the apex of the left ventricle.

\section{HISTOLOGICAL METHODS}

The left ventricular biopsy material was divided; one half was paraffin embedded, and $5 \mu \mathrm{m}$ thick sections were stained with haematoxylin and eosin and Miller's elastic van Gieson. Hypertrophy was assessed by measuring at least 100 myocardial fibres by means of the Projectina microscope. Accurate assessment of fibre diameter was at times difficult, particularly when the interstitial fibrous tissue was severely increased. Myocardial fibre diameter was considered abnormal if it measured more than $15 \mu \mathrm{m} .{ }^{6}$ Degenerative changes, though relatively non-specific, were also noted.

Miller's elastic van Gieson stain was used to delineate collagen tissue and other components of the interstitium.

Interstitial fibrous tissue was graded as follows:

(i) Absent - no increase in interstitial collagen tissue (Fig. 1).

(ii) Mild - occasional foci of increased collagen tissue between adjacent myocardial fibres.

(iii) Moderate - widespread increase of collagen tissue in the interstitium not exceeding $15 \mu \mathrm{m}$.

(iv) Severe - widespread increase in the collagen tissue of the interstitium of $16 \mu \mathrm{m}$ or more (Fig. 2).

Focal and confluent areas of fibrous replacement were also noted. Grades I and II were considered normal morphological alterations.

\section{HISTOCHEMISTRY}

The remaining half of the biopsy tissue was immediately frozen in "Freon" (BOC), precooled in liquid nitrogen, and stored at $-70^{\circ} \mathrm{C}$. Five $\mu \mathrm{m}$ thick cryostat sections were then analysed using standard enzyme histochemical methods ${ }^{78}$ for myofibrillar calcium dependent adenosine triphosphatase (ATPase), succinate dehydrogenase, and glycogen.

\section{ANALYSIS OF DATA}

Postoperative observations were compared with preoperative (control) measurements using the paired Student's t test. Endomyocardial biopsy data were correlated with those obtained from the larger operative specimens in 15 cases using the coefficient of variance (expressed as a percentage). 


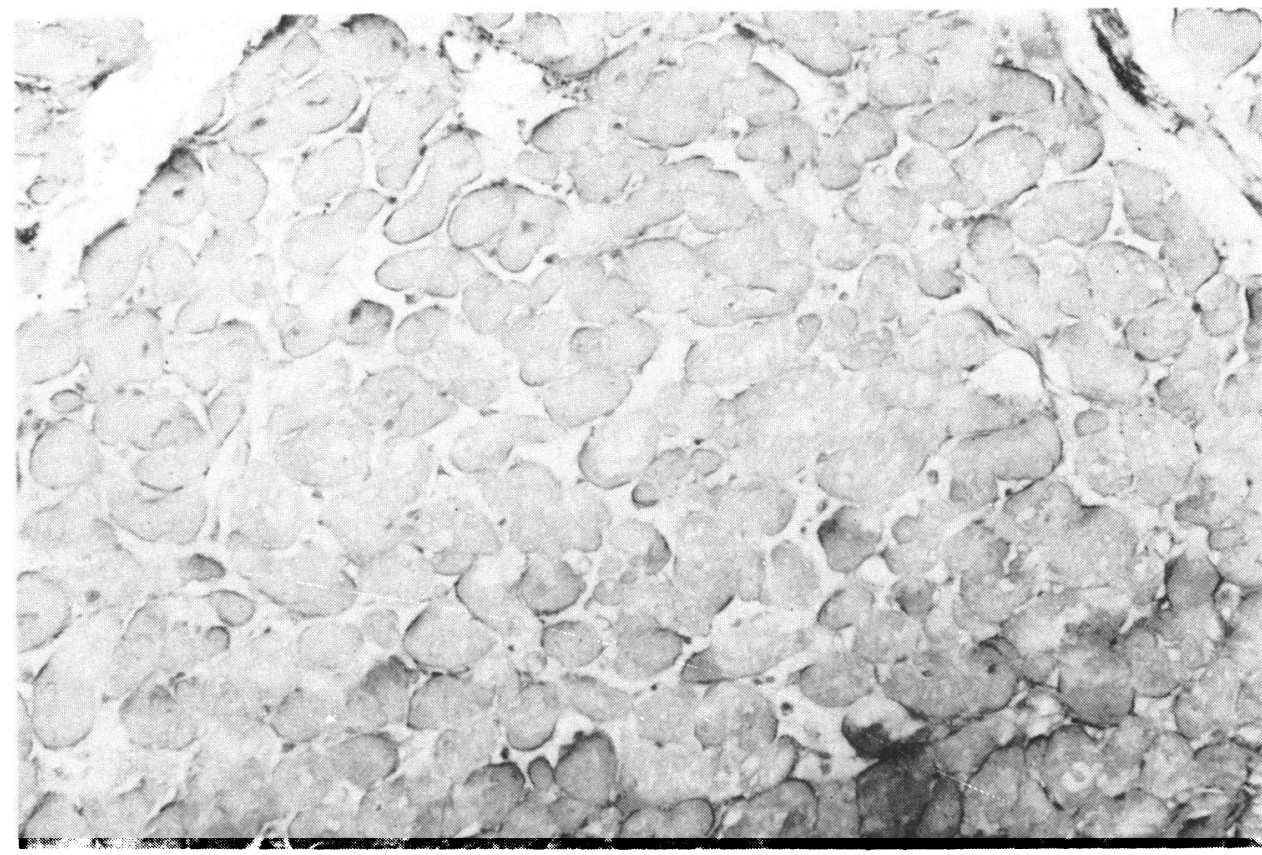

Fig. 1 Postoperative left ventricular biopsy from a patient with aortic regurgitation and normal echocardiographic end-diastolic dimension after surgery (group A). The photomicrograph shows myocardial hypertrophy but no increase in the interstitial collagen tissue. (Miller's elastic van Gieson, original magnification $\times 200$.)

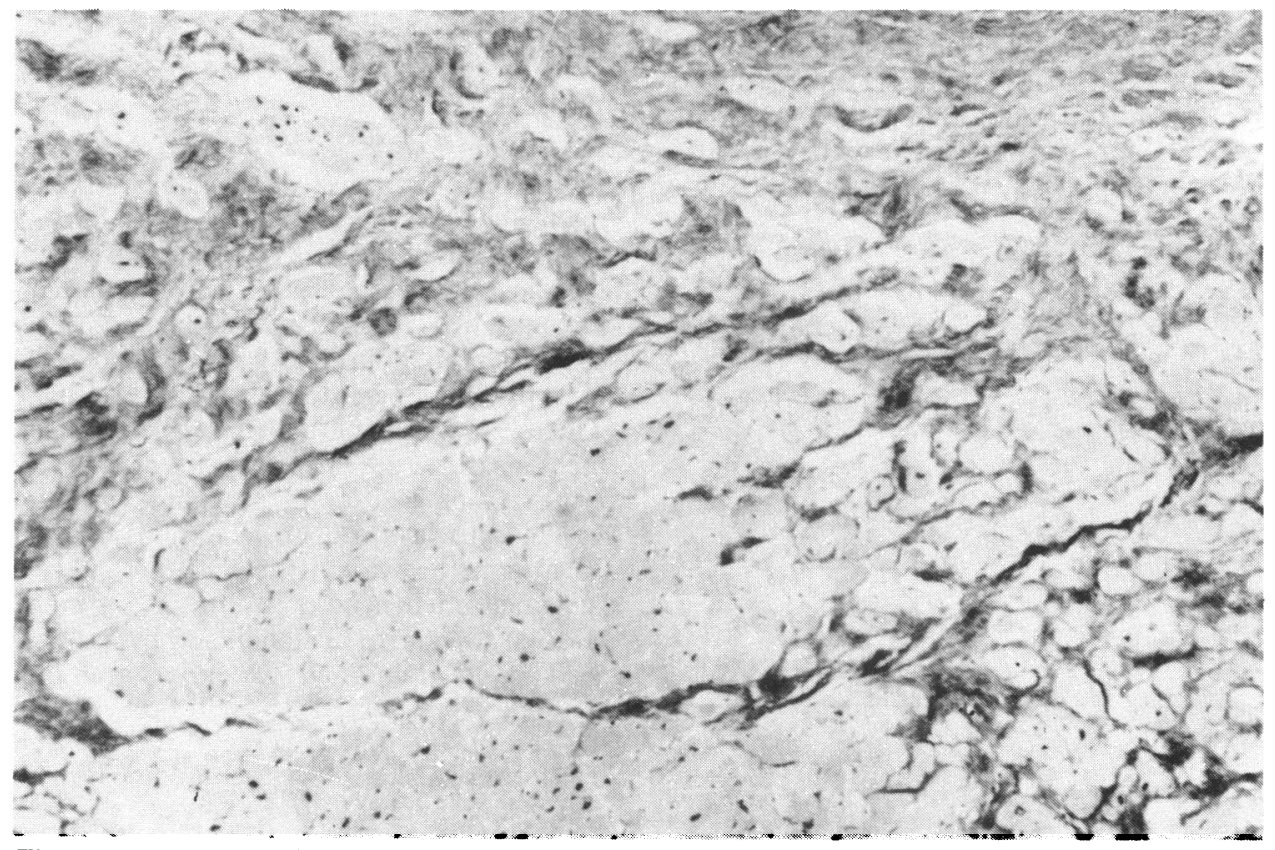

Fig. 2 Postoperative left ventricular biopsy from a patient with aortic regurgitation and persistent ventricular dilatation despite satisfactory valve function (group B). The photomicrograph shows a severe increase in interstitial fibrous tissue as well as subendocardial confluent fibrous replacement. The mildly thickened endocardium can be discerned at the upper half of the illustration. (Miller's elastic van Gieson, original magnification $\times 128$.) 


\section{Results}

\section{ELECTROCARDIOGRAPHY}

Of the 67 patients with chronic aortic regurgitation, 64 had electrocardiographic evidence of left ventricular hypertrophy before surgery. The voltages decreased after surgery in $50(78 \%)$ and returned to normal in 19 of these 50 patients. Voltage changes took place within six to 12 months after operation. Of the other 17 , left ventricular hypertrophy was unchanged in five patients, and nine patients developed progressive ventricular conduction abnormalities or bundlebranch block. The presence of pre- and perioperative conduction defects precluded analysis of hypertrophy in the remaining three patients.

\section{ECHOCARDIOGRAPHY}

By means of echocardiographic assessment of the left ventricular end-diastolic dimension performed at regular intervals for at least three years after operation, patients were divided into two groups (Fig. 3). Group A (51 patients) had normal end-diastolic dimensions $(<52 \mathrm{~mm}$ ) after operation (usually within three months of valve replacement); in group B (16 patients) the end-diastolic dimension remained greater than normal. Three patients in group B died in the follow-up period. Though patients in group B tended to have larger transverse dimensions before operation, there was no significant difference between the preoperative enddiastolic dimension of patients in both groups. Overall muscle cross-section area showed a gradual reduction in the first year after operation $\left(32 \pm 7 \mathrm{~cm}^{2}\right.$ to $\left.22 \pm 6 \mathrm{~cm}^{2}\right)$ $(p<0.01)$. Despite a decrease of more than one-third in this index of muscle mass, postoperative values were

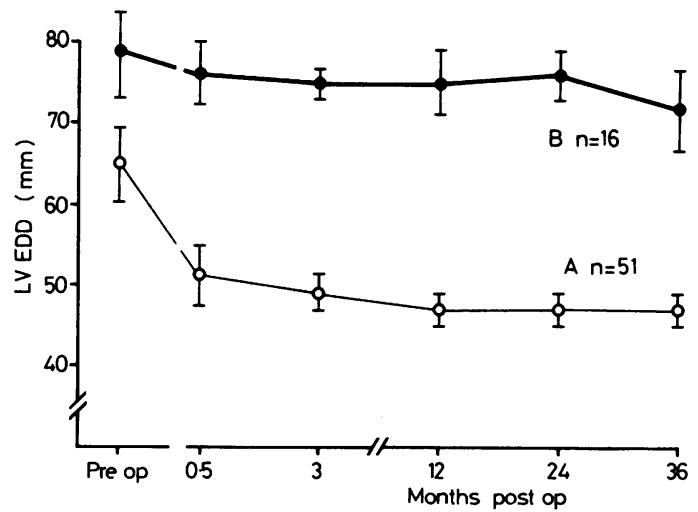

Fig. 3 Serial pre-and postoperative echocardiographic left ventricular end-diastolic diameters (LV EDD) from the 67 patients with volume overload resulting from aortic regurgitation. Values expressed average $\pm S E M$. Patients in group A achieved normal end-diastolic dimension after aortic valve replacement; 16 patients had persistent postoperative enlargement (group B). still significantly raised above the normal range at the latest follow-up $(\mathrm{p}<0.05)$. The reduction of ventricular mass was paralleled by a reduction in the electrocardiographic voltages, and patients with persistently increased voltages on electrocardiographs had grossly abnormal estimates of muscle mass.

\section{HISTOLOGY}

\section{Preoperative}

Preoperative histological data are shown in Table 1. Mean myocardial fibre diameter was $26 \mu \mathrm{m}$ for the 51 patients in group A and $33 \mu \mathrm{m}$ for the 16 patients in group B. Abnormally increased levels of collagen (grades III and IV) were noted in only seven out of the 51 cases $(13.7 \%)$ in group $A$; while 11 out of the 16 patients $(69 \%)$ with persistent postoperative dilatation (group B) had abnormal fibrous content.

Preoperative histology was normal in 49 out of the 67 patients in this series; 44 (90\%) of these 49 cases experienced postoperative clinical and echocardiographic improvement (group A), while in the other five cases the ventricular function was abnormal after valve replacement (group B). The biopsies were abnormal in 18 patients before valve replacement; operation did little to alter the course of the disease in $11(61 \%)$ of these 18 cases.

Only a small variance was present between the histological data derived from the smaller bioptome tissue samples and those obtained from the larger operative specimens. The coefficient of variance for the 15 cases compared was $7 \cdot 6 \%$.

\section{Postoperative}

Histological data were obtained before valve replacement and on average one year after operation in 13 patients (Table 2). In this subgroup of 13 patients with biopsies before and after valve replacement, five patients had normal echocardiographic ventricular dimension after surgery (group A) and eight patients (group B) had persistent dilatation and hypertrophy. The mean muscle fibre diameter before valve replacement measured $29.3 \mu \mathrm{m}$ in the five tissue samples from group $\mathrm{A}$, and $34 \cdot 1 \mu \mathrm{m}$ in the eight biopsies from group B. This muscle fibre diameter decreased significantly to $23.4 \mu \mathrm{m}$ in the five patients from group $\mathrm{A}(\mathrm{p}<0.01)$ but remained unchanged $(32.5 \mu \mathrm{m})$ in the eight patients with postoperative dilatation and hypertrophy (Table 2 ). Those in group A had either no fibrous tissue (grade I, three cases) (Fig. 1) or mild (grade II, two cases) increase in the fibrous content in the pre- and postoperative biopsies. Moderate (grade III, four patients) and severe (grade IV, three patients) (Fig. 2) increase in fibrous tissue was documented before and after valve replacement in seven of the eight patients restudied from group B. The remaining patients from this group had grade II fibrous content. 
Table 1 Preoperative histology: 67 patients surviving aortic valve replacement, divided retrospectively into echocardiographic groups $A$ (normal dimensions) and $B$ (postoperative dilatation)

\begin{tabular}{|c|c|c|}
\hline & $\begin{array}{l}\text { Group } A \\
(n=51)\end{array}$ & $\begin{array}{l}\text { Group B } \\
(n=16)\end{array}$ \\
\hline $\begin{array}{ll}\begin{array}{l}\text { Mean myocardial fibre diameter }(\mu \mathrm{m}) \\
\text { Interstitial collagen }\end{array} & \text { Grade I to II } \\
& \text { Grade III to IV } \\
\text { Histochemistry } & \begin{array}{l}\text { Adenosine triphosphatase (ATPase) } \\
\text { Succinate dehydrogenase (SDH) } \\
\text { Glycogen }\end{array}\end{array}$ & $\begin{array}{l}26 \\
(44) \\
(7)^{\star} \\
\text { Normal (45), abnormal (5) } \\
\text { Normal (46), abnormal (5) } \\
\text { Normal (48), abnormal (3) }\end{array}$ & $\begin{array}{l}33 \\
(5) \\
(11)^{\star} \\
\text { Normal (5), abnormal (11) } \\
\text { Normal (8), abnormal (8) } \\
\text { Normal (6), abnormal (10) }\end{array}$ \\
\hline
\end{tabular}

^All patients with severely increased fibrous content had abnormal enzyme activity.

Table 2 Comparison of pre- and postoperative histological and histochemical data in 13 patients with left ventricular biopsies before and after aortic valve replacement

\begin{tabular}{|c|c|c|c|c|}
\hline & \multicolumn{2}{|l|}{ Group $A(n=5)$} & \multicolumn{2}{|l|}{ Group B $(n=8)$} \\
\hline & Preoperative & Postoperative & Preoperative & Postoperative \\
\hline $\begin{array}{l}\text { Mean myocardial fibre } \\
\text { diameter }(\mu \mathrm{m}) \\
\text { Interstitial collagen }\end{array}$ & $\begin{array}{l}29 \cdot 3 \\
\text { Grade I to II (5) }\end{array}$ & $\begin{array}{l}23 \cdot 4 \\
\text { Grade I to II (5) }\end{array}$ & $\begin{array}{l}34 \cdot 1 \\
\text { Grade III to IV }{ }^{\star}(7) \\
\text { Grade II (1) }\end{array}$ & $\begin{array}{l}32 \cdot 5 \\
\text { Grade III to IV }(7) \\
\text { Grade II (1) }\end{array}$ \\
\hline $\begin{array}{l}\text { Histochemistry } \\
\text { Adenosine triphosphatase } \\
\text { (ATPase) } \\
\text { Succinate dehydrogenase }\end{array}$ & Normal & Normal & Normal (2), abnormal (6) & Normal (2), abnormal (6) \\
\hline $\begin{array}{l}\text { (SDH) } \\
\text { Glycogen }\end{array}$ & $\begin{array}{l}\text { Normal } \\
\text { Normal }\end{array}$ & $\begin{array}{l}\text { Normal } \\
\text { Normal }\end{array}$ & $\begin{array}{l}\text { Normal (3), abnormal (5) } \\
\text { Normal (4), abnormal (4) }\end{array}$ & $\begin{array}{l}\text { Normal (4), abnormal (4) } \\
\text { Normal (4), abnormal (4) }\end{array}$ \\
\hline
\end{tabular}

^All patients with severely increased fibrous content had abnormal enzyme activity.
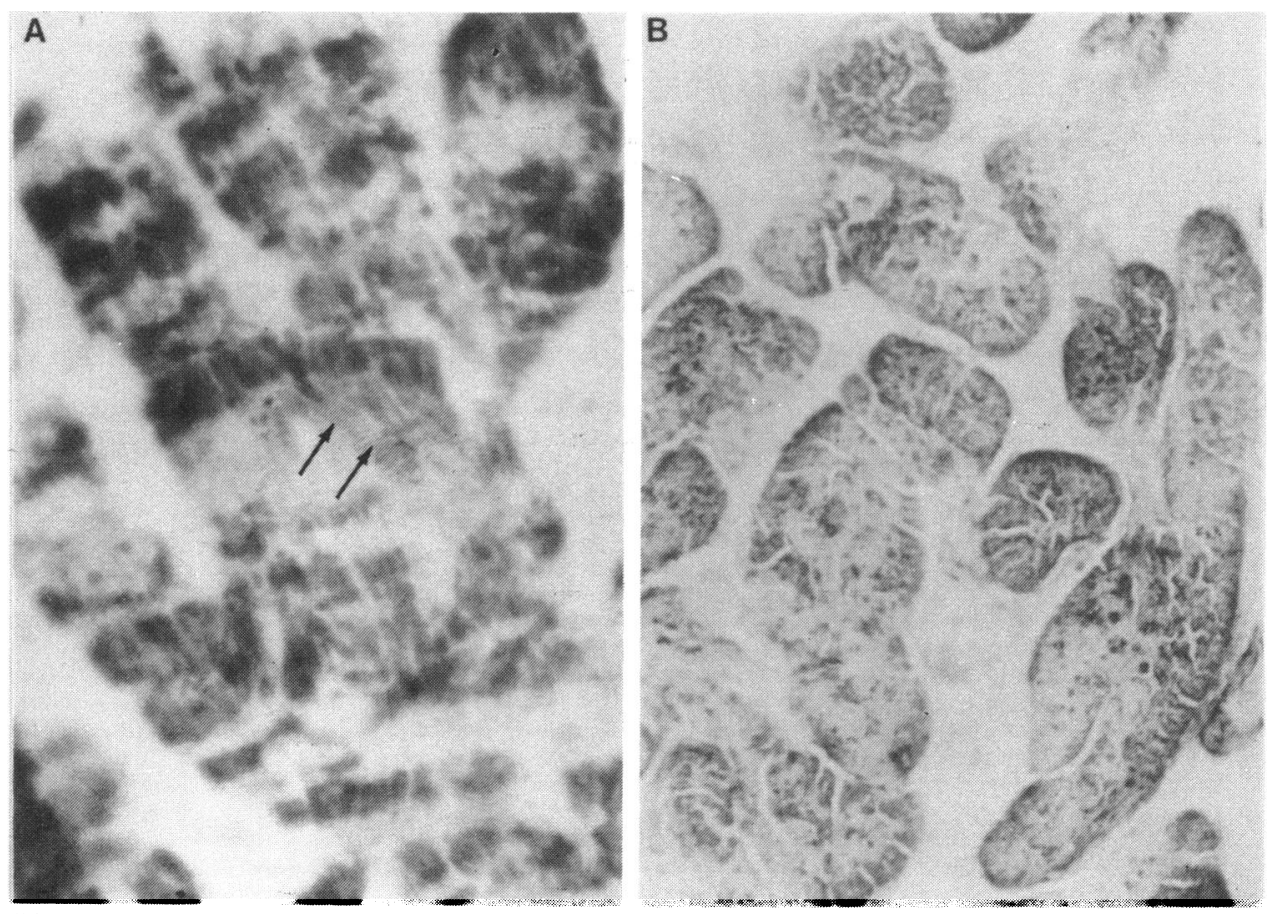

Fig. 4 (A) Normal myofibrillar ATPase activity discretely localised on the cross-striations (arrows) in a biopsy sample from a patient with normal postoperative ventricular function and echocardiographic dimensions. (Original magnification $\times 800$.) (B) Patchy decreased levels in tissue sample from a case of postoperative impaired contractility. The discrete localisation is destroyed and there are only coarse clumps of activity, with distorted muscle in the intervening spaces. (Original magnification $\times 460$.) Both $(A)$ and $(B)$ cut obliquely. 


\section{HISTOCHEMISTRY}

Preoperative histochemical studies were normal in 45 (88\%) out of the 51 biopsies from patients in group A (Table 1), and all five patients from this group who were restudied had normal enzyme activity (Table 2 ). Reduced levels of glycogen and of myofibril associated calcium-dependent ATPase and of the mitochondrial enzyme succinate dehydrogenase correlated with impaired ventricular function and cardiac dilatation after operation (Table 1) and one or more of these features were present in $11(69 \%)$ out of the 16 patients in group B. Six out of the eight patients with unsuccessful outcome after surgery who were reinvestigated had reduced ATPase levels in the preoperative biopsies (Fig. 4B) and these changes persisted in the group of 13 patients studied before and after valve replacement (Table 2), decreased levels of succinate dehydrogenase were documented in five out of the 8 intraoperative samples from patients included in group B (Fig. 5B), and succinate dehydrogenase was abnormal in four of the postoperative biopsies. Persistently abnormal levels of glycogen were noted before and after operation in four patients from group B (Table 2).
All patients with abnormal histochemistry also had abnormal interstitial fibrous content (see Tables 1 and 2).

Differences in histology and histochemistry between patients included in groups A and B were not altogether clear cut, as five patients with normal biopsy studies deteriorated after operation and seven patients with abnormal levels of fibrous content and/or enzyme markers experienced clinical and echocardiographic improvement.

\section{POSTOPERATIVE ANGIOGRAPHY}

Ten out of the 21 patients restudied had normal postoperative ventricular function and these 10 cases included seven patients in whom previously impaired contractility improved significantly after surgery. The other 11 patients had large angiographic end-diastolic volumes and an ejection fraction of less than $45 \%$ after valve replacement; all these 11 cases were in the echocardiographic group B. Ventricular function and regional wall motion had either remained impaired (Fig. 6) or had deteriorated after operation in these 11 patients.
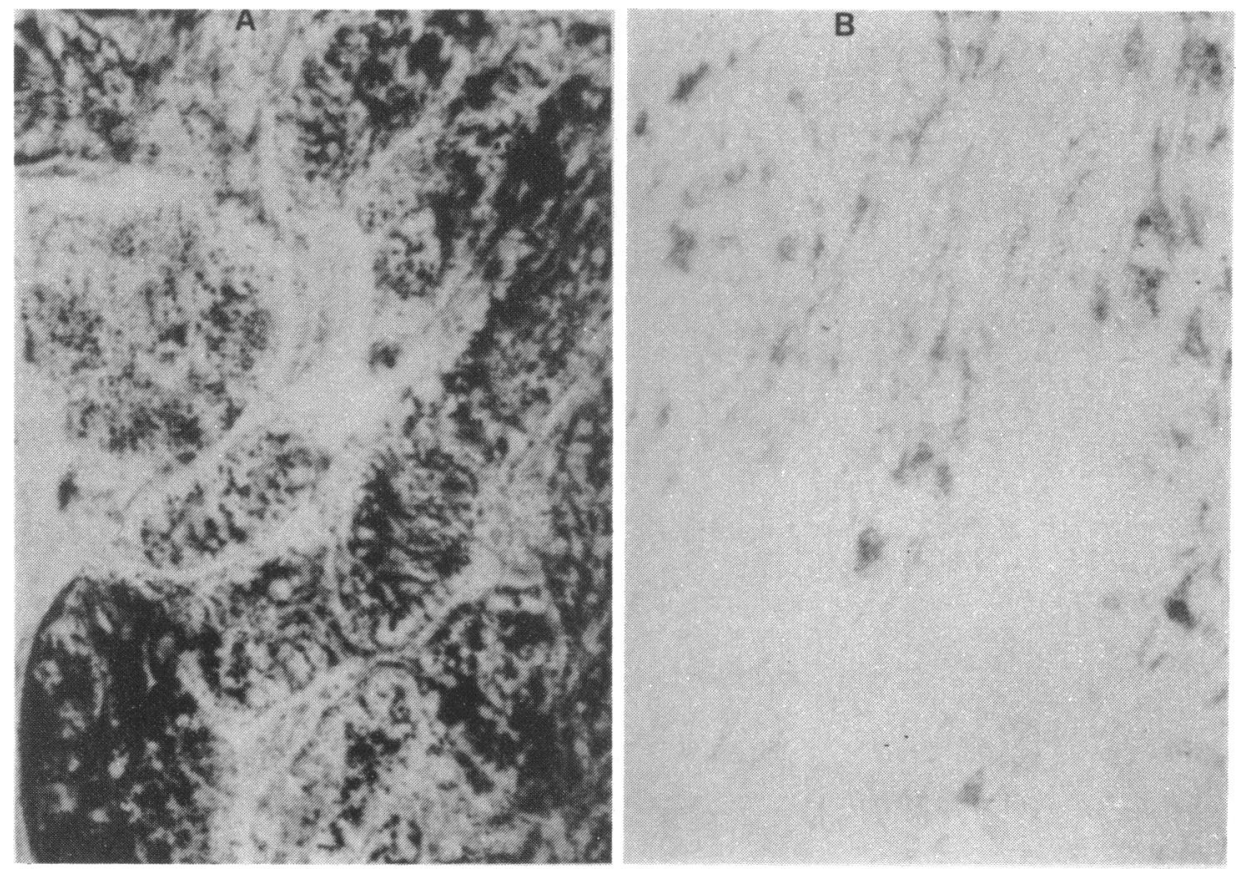

Fig. 5 (A) Succinate dehydrogenase, MTT, nitro-blue formazan method. ${ }^{8}$ Normal levels of succinate dehydrogenase reaction in a biopsy sample from a patient with good postoperative ventricular function (from group A). (B) Abnormally decreased levels of succinate dehydrogenase in a tissue sample obtained at postoperative cardiac catheterisation in a patient from group $B$ who died a few months later from intractable heart failure two years after valve replacement in spite of satisfactory valve function. Myofibrillar staining is lost, and the reaction is confined to a few sarcosomes. 

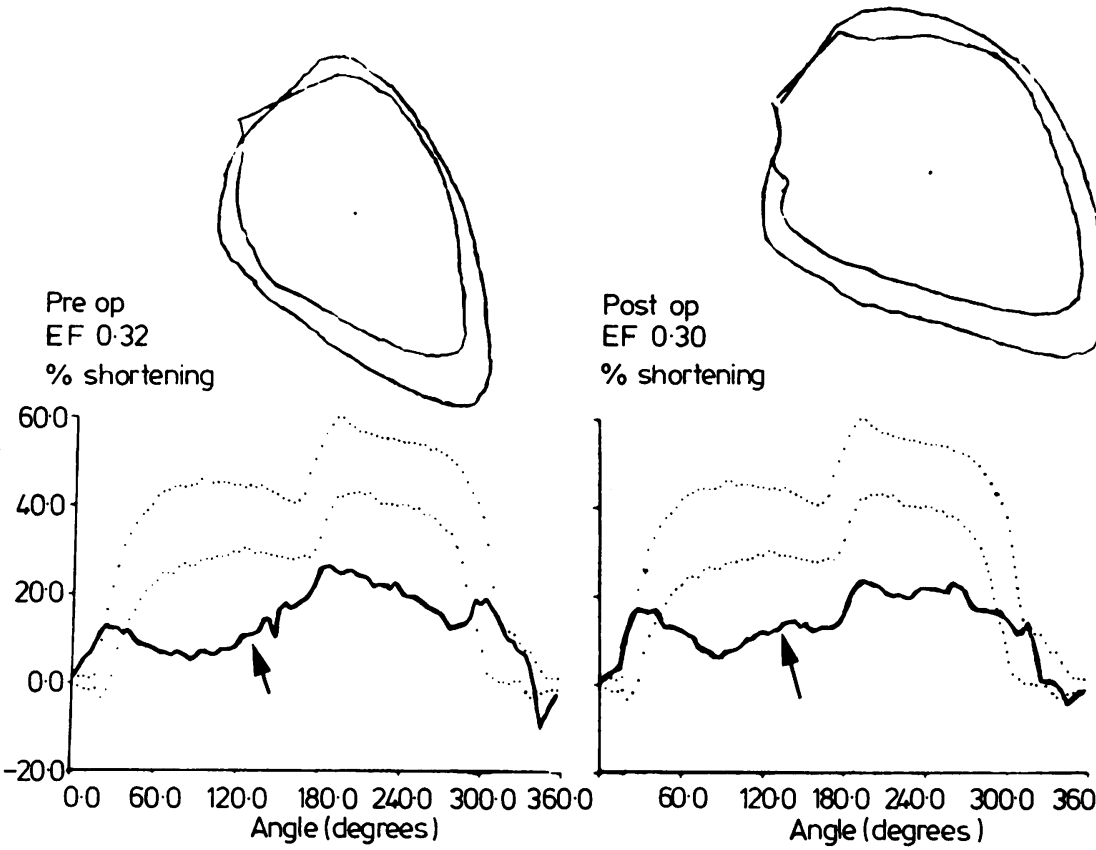

$\%$ shortening

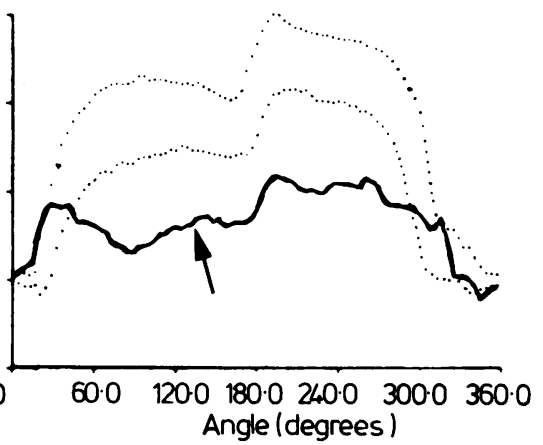

Fig. 6 Radial analysis of segmental wall motion before (left) and after (right panel) aortic valve replacement for chronic volume overload. The bottom plots show the percentage shortening (vertical axis) against the radial angle (horizontal axis). Dotted lines represent $\pm S D$ from the mean values obtained in a group of normal patients; the arrowed line is that of a patient with aortic regurgitation and normal coronary arteries. The preoperative study (left) showed severe generalised hypokinesia; ventricular function was grossly impaired in the postoperative study (right) performed 16 months after operation, despite satisfactory valve function.

\section{Discussion}

Aortic valve replacement in chronic volume overload usually leads to striking symptomatic and haemodynamic improvement. This is accompanied by a reduction in left ventricular hypertrophy and chamber size, and most patients achieve normal or near normal end-diastolic volumes after operation. In some instances surgical correction does little to alter the course of the disease, and these patients usually develop progressive cardiac failure. Thus, optimum timing of valve replacement in chronic volume overload is a difficult and challenging problem..$^{12}$

Most of the electrocardiographic voltage changes occurred within one year of valve replacement and studies after this period showed stable voltage measurements. Our group of patients with postoperative progressive ventricular conduction abnormalities or bundle-branch block on the electrocardiogram generally had persistent ventricular hypertrophy or dilatation. These probably represented late, irreversible myocardial changes, and though some of these patients experienced clinical improvement, they were clearly at risk from subsequent death from congestive failure.
Angiography and echocardiography are the methods of choice for evaluating ventricular hypertrophy, and various studies have shown that, though considerable regression of hypertrophy occurs after aortic valve replacement, this is usually incomplete. ${ }^{9-13}$ In our study, the difference between the patients in both echocardiographic groups (Fig. 3) could not be explained by the value of the original end-diastolic dimension. Our data suggest that preoperative echocardiography cannot define the type and degree of left ventricular dilatation and hypertrophy which is irreversible. Though some studies have suggested that patients should undergo surgery once ventricular systolic dysfunction is detected echocardiographically, ${ }^{11} 14$ other investigators, ${ }^{315}$ like ourselves, could not define this irreversible dysfunction from preoperative data.

Our angiographic studies were mostly performed in patients whose postoperative course did not follow the expected pattern, and were therefore unrepresentative of the overall group. While seven patients with abnormal preoperative haemodynamics, however, showed an improvement in ventricular function, 11 others showed either no change or a deterioration in postoperative contractility (Fig. 6). Angiographic systolic function in this series was therefore unhelpful 
as a predictor of postoperative haemodynamics.

The diagnostic capability of histological evaluation is well established, ${ }^{16}$ but there are few studies correlating pathological data with clinical findings. In this study we compared the biopsy findings with clinical and non-invasive data after correction of severe chronic aortic regurgitation, to establish whether histological changes were a contributory factor to impaired postoperative function.

Fibrosis, often extensive, may accompany myocardial hypertrophy in valvular heart disease, and it is likely that myocardial hypertrophy is less reversible in those patients with considerable preoperative fibrosis. Moderately or severely increased interstitial fibrous tissue (grade III or IV) (Fig. 2) and loss of myofibrillar components from the massively hypertrophied myocardial cells correlated with postoperative ventricular dilatation and impaired function (Tables 1 and 2 ). Most of the patients reinvestigated from group B had severe postoperative hypertrophy (mean $32.5 \mu \mathrm{m}$ ) and persistently increased fibrous collagen tissue. The three patients who died from congestive failure during follow-up were in this group B. Similar correlation between postoperative symptoms of cardiac failure and preoperative fibrosis has recently been reported. ${ }^{17}$

Histochemical studies on the tissues obtained before and after surgery from patients with postoperative cardiac dilatation (group B) showed abnormalities in the levels of certain enzyme markers (Tables 1 and 2). Eleven out of these 16 patients had reduced levels of myofibril associated $\mathrm{Ca}^{++}$dependent ATPase before valve replacement, and this abnormality was documented in six out of the eight patients restudied from this group. It is likely that this was associated with grossly impaired ventricular function ${ }^{18}$; the defective utilisation of high energy phosphates by the myofibrils and decreased metabolic substrates such as glycogen could also have contributed to further depression of the contractile function. Chronic mechanical overloading in rats may cause an isoenzymic shift in the composition of cardiac myosin ${ }^{19}$ which could also partially account for the lower ATPase activity and decreased contractility.

The decreased level of the mitochondrial enzyme succinate dehydrogenase in the biopsies from patients in group B (Tables 1 and 2) is of interest, suggesting perhaps an irreversible abnormality in the properties or function of mitochondria. ${ }^{20}$ Further work on the biochemical basis of physiological and pathological adaptations will undoubtedly elucidate the relevance of these histochemical observations.

A normal preoperative biopsy was sensitive in identifying patients with an eventual successful outcome after valve replacement; the predictive value of this test was $89 \%$. Five patients, however, with normal preoperative histological studies deteriorated post- operatively, with echocardiographic evidence of persistent dilatation and hypertrophy. As prosthetic $\stackrel{5}{\rightarrow}$ valve function was normal in these five patients, it can be speculated that operative factors such as myocardial ischaemia during the operation could have adversely affected cardiac haemodynamics. Histochemical changes resulting from cardiopulmonary bypass have been documented; methods of myocardial protection during this type of surgery have been evaluated using histochemical variables. ${ }^{21}$

An abnormal biopsy had a lower sensitivity in predicting an unsuccessful outcome after valve replacement. Among 18 patients with abnormal myocardial histology or histochemistry, $11(61 \%)$ developed persistent dilatation and hypertrophy after surgery, and three of these 11 patients died from cardiac failure during the follow-up period. The fact that one-third of the patients with abnormal biopsies improved clinically and echocardiographically, however, remains unexplained and reduces the prognostic accuracy of this method.

Because of the possible considerable topographic variation of the structured composition of the myocardium in chronic aortic regurgitation, we also compared data from the small bioptome biopsies with those obtained from the larger operative specimen in 15 patients before valve replacement. A good correlation was present, and these data confirm our recent observation $^{22}$ that, provided a minimum of four biopsies are obtained, small tissue samples are accurate in evaluating morphology and can therefore be used to predict prognosis.

\section{IMPLICATIONS OF STUDY}

The serial application of electrocardiography and echocardiography to patients undergoing valve replacement for chronic severe aortic regurgitation documented regression of hypertrophy and chamber size within 12 months of surgery in all cases experiencing haemodynamic improvement. Those patients who had persistently increased patterns of myocardial hypertrophy and abnormal end-diastolic dimensions in the presence of normal prosthetic (homograft) function usually had persistent, irreversibly depressed myocardial function postoperatively (Table 3). Preoperative non-invasive and angiographic characteristics could not predict ventricular function after operation. Thus we could not define precisely what level of depressed ventricular performance or what degree of dilatation and myocardial hypertrophy constitutes an irreversible state from these data. Though operative factors such as myocardial protection during cardiopulmonary bypass undoubtedly influence postoperative cardiac performance, preoperative histological and histochemical data were useful in delineating irreversible morphological and functional changes contributing to a 
Table 3 Pre-and postoperative pointers to irreversible morphological changes contributing to a depressed cardiac function after surgery for chronic aortic regurgitation

(1) Preoperative ventricular biopsy data

Massively increased myocardial fibre diameter $(>30 \mu \mathrm{m})$ Grossly abnormal fibrous content

Reduced levels of histochemical markers (ATPase, succinate dehydrogenase, glyc gen)

(2) Postoperative data

Electrocardiography

(A) Non-invasive (i) Persistently increased left ventricular voltages

Progressive conduction abnormalities 6 to 12 months after operation Echocardiography

(ii) Abnormal end-diastolic dimension six months after surgery

Abnormal estimates of muscle mass 12 months after surgery

(B) Invasive Angiography

Impaired systolic function and regional wall motion despite satisfactory valve function and normal coronary anatomy

depressed cardiac function. These data may therefore be of prognostic importance.

\section{Conclusion}

Because irreversible myocardial depression may be present before the development of significant symptoms, aortic valve replacement may sometimes be recommended in patients with aortic regurgitation and minimal symptoms. Our echocardiographic and angiographic data could not define the type and degree of ventricular dysfunction which was irreversible. Preoperative ventricular biopsies suggest that extensive morphological changes contribute to depressed postoperative function, and these histological data appear to be of prognostic significance.

\section{References}

1 Selzer A. Cardiac valve replacement: an unanswered question. Am f Cardiol 1976; 37: 322-4.

2 Rahimtoola SH. Early valve replacement for preservation of ventricular function? Am $\mathcal{F}$ Cardiol 1977; 40: 472-5.

3 Schuler G, Peterson KL, Johnson AD, et al. Serial noninvasive assessment of left ventricular hypertrophy and function after surgical correction of aortic regurgitation. Am f Cardiol 1979; 44: 585-94.

4 Rickards A, Seabra-Gomes R, Thurston P. The assessment of regional abnormalities of the left ventricle by angiography. Eur $\mathcal{F}$ Cardiol 1977; 5: 167-82.

5 Brooksby IAB, Jenkins BS, Coltart DJ, Webb-Peploe MM, Davies MJ. Left-ventricular endomyocardial biopsy. Lancet 1974; ii: 1222-5.

6 Olsen EGJ. The pathology of the heart. 2nd ed. London: Macmillan, 1982: 49-51.

7 Bancroft JD, Stevens A. Histopathological stains and their diagnostic uses. Edinburgh: Churchill Livingstone, 1975: 128-33.
8 Pearce AGE. Histochemistry, theoretical $\&$ applied. vol. 2. Edinburgh: Churchill Livingstone, 1970.

9 Henry WL, Bonow RO, Borer JS, et al. Observations on the optimum time for operative intervention for aortic regurgitation: I: Evaluation of the results of aortic valve replacement in symptomatic patients. Circulation 1980; 61: 471-83.

10 Pantely G, Morton M, Rahimtoola SH. Effects of successful, uncomplicated valve replacement on ventricular hypertrophy, volume, and performance in aortic stenosis and in aortic incompetence. $\mathcal{f}$ Thorac Cardiovasc Surg 1978; 75: 383-91.

11 Clark DG, McAnulty JH, Rahimtoola SH. Valve replacement in aortic insufficiency with left ventricular dysfunction. Circulation 1980; 61: 411-21.

12 Mirsky I, Henschke C, Hess OM, Krayenbuehl HP. Prediction of postoperative performance in aortic valve disease. Am 7 Cardiol 1981; 48: 295-303.

13 Gaasch WH, Andrias CW, Levine HJ. Chronic aortic regurgitation: the effect of aortic valve replacement on left ventricular volume, mass and function. Circulation 1978; 58: $825-36$.

14 Henry WL, Bonow RO, Rosing DR, Epstein SE. Observations on the optimum time for operative intervention for aortic regurgitation: II. Serial echocardiographic evaluation of asymptomatic patients. Circulation 1980; 61: 484-92.

15 Boucher CA, Bingham JB, Osbakken MD, et al. Early changes in left ventricular size and function after correction of left ventricular volume overload. $A m \mathcal{F}$ Cardiol 1981; 47: 991-1004.

16 Bolte HD. Myocardial biopsy. Diagnostic significance. New York: Springer Verlag, 1980: 1-96.

17 Oldershaw PJ, Brooksby IAB, Davies MJ, Coltart DJ, Jenkins BS, Webb-Peploe MM. Correlations of fibrosis in endomyocardial biopsies from patients with aortic valve disease. Br Heart f 1980; 44: 609-11.

18 Berson G, Swynghedauw B. Cardiac myofibrillar ATPase and electrophoretic pattern in experimental heart failure produced by a two-step mechanical overloading in the rat. Cardiovasc Res 1973; 7: 464-9.

19 Mercadier JJ, Lompre AM, Wisnewsky C, et al. Myosin isoenzymic changes in several models of rat cardiac hypertrophy. Circ Res 1981; 49: 525-32.

20 Peters TJ, Wells G, Oakley CM, et al. Enzymic analysis of endomyocardial biopsy specimens from patients with cardiomyopathies. Br Heart $\mathcal{F}$ 1977; 39: 1333-9.

21 Canković-Darracott S, Braimbridge MV, Williams BT, Bitensky L, Chayen J. Myocardial preservation during aortic valve surgery. Assessment of five techniques by cellular chemical and biophysical methods. $\mathcal{F}$ Thorac Cardiovasc Surg 1977; 73: 699-706.

22 Baandrup U, Florio RA, Olsen EGJ. Do endomyocardial biopsies represent the morphology of the rest of the myocardium? A quantitative light microscopic study of single vs. multiple biopsies with the King's bioptome. Eur Heart F 1982; 3: 171-8.

Requests for reprints to Dr R M Donaldson, National Heart Hospital, Westmoreland Street, London W1M 8BA. 